Cite as:

Golmakani, M. T.; Mendiola, J. A.; Rezaei, K.; Ibáñez, Elena "Pressurized limonene as an alternative bio-solvent for the extraction of lipids from marine microorganisms" (2014) Journal of Supercritical Fluids 92: 1-7

http://dx.doi.org/10.1016/j.supflu.2014.05.001

\title{
Pressurized limonene as an alternative bio-solvent for the extraction of
}

\section{lipids from marine microorganisms}

\author{
M.-T. Golmakani ${ }^{a}$, J.A. Mendiola ${ }^{b}$, K. Rezaei ${ }^{c}$, E. Ibáñez ${ }^{\text {t }}$
}

${ }^{a}$ Department of Food Science and Technology, School of Agriculture, Shiraz University, Shiraz, Iran Fax: (+98)711-2286110; Tel: (+98)711-6138243.E-mail: golmakani@,shirazu.ac.ir

${ }^{b}$ Institute of Food Science Research (CIAL), CSIC-UAM, Madrid, Spain. Fax: (+34) 910017905 ;

Tel: (+34)910017900.E-mail:j.mendiola@csic.es and elena@ifi.csic.es

${ }^{c}$ Department of Food Science, Engineering, and Technology, University of Tehran, Karaj, Iran. Fax: (+98)26-32248804; Tel: (+98)26-32235124. E-Mail: krezaee@,ut.ac.ir

*Corresponding author:

Elena Ibáñez elena@ifi.csic.es

Instituto de Investigación en Ciencias de la Alimentación (CIAL-CSIC)

C/ Nicolás Cabrera, 9 (Campus de Cantoblanco)

28049, Madrid, Spain

Fax: +34910017 905; Tel: +34910017956 
Cite as:

Golmakani, M. T.; Mendiola, J. A.; Rezaei, K.; Ibáñez, Elena "Pressurized limonene as an alternative bio-solvent for the extraction of lipids from marine microorganisms" (2014) Journal of Supercritical Fluids 92: 1-7

http://dx.doi.org/10.1016/j.supflu.2014.05.001

22 Abstract:

23 A fast and green process for the isolation of high value lipids from different marine microorganisms is

${ }_{24}$ presented involving the use of limonene, a green biodegradable solvent, as an alternative to traditional

${ }_{25}$ hexane extraction. The optimized process is based on pressurized liquid extraction (PLE) at $200^{\circ} \mathrm{C}$ for 15 min using limonene:ethanol $(1: 1, \mathrm{v} / \mathrm{v})$ as extracting solvent. Under these conditions, lipids were extracted from different microalgae such as Spirulina, Phormidium, Anabaena and Stigeoclonium and

${ }_{28}$ their composition in terms of fatty acids were studied by using a Fast-GC-MS method and compared with the original content in the raw material. The extraction method provided the best results in terms of extraction yield for Spirulina, meanwhile the highest amount of $\omega$-3 fatty acids were obtained from

31 Stigeoclonium.

\section{Keywords:}

PLE, limonene, Spirulina, Anabaena, Stigeoclonium, Phormidium, $\gamma$-linolenic acid, PUFAs 
Cite as:

Golmakani, M. T.; Mendiola, J. A.; Rezaei, K.; Ibáñez, Elena "Pressurized limonene as an alternative bio-solvent for the extraction of lipids from marine microorganisms" (2014) Journal of Supercritical Fluids 92: 1-7

http://dx.doi.org/10.1016/j.supflu.2014.05.001

${ }_{56} \quad \mathrm{~W} / \mathrm{W}[14,15]$.

In the present study, the cyanobacteria Arthrospira platensis (Spirulina), Phormidium sp. and ${ }_{58}$ Anabaena planctonica, together with the fresh water microalga Stigeoclonium sp. from the class 
Cite as:

Golmakani, M. T.; Mendiola, J. A.; Rezaei, K.; Ibáñez, Elena "Pressurized limonene as an alternative bio-solvent for the extraction of lipids from marine microorganisms" (2014) Journal of Supercritical Fluids 92: 1-7

http://dx.doi.org/10.1016/j.supflu.2014.05.001

Chlorophyceae (Chlorophyta) have been studied due to their interesting lipid profile, being both a promising feedstock source for biodiesel production [16] and a valuable source of PUFAs. In the search for alternative media for the extraction of microalgae lipids, supercritical $\mathrm{CO}_{2}[15,17]$ and pressurized liquid extraction (PLE) [18, 19] have been practiced quite extensively. The use of compressed fluids can result in less solvent consumption and shorter extraction times, when compared to traditional Soxhlet extraction. In a previous work, current authors suggested the employment of expanded ethanol with $\mathrm{CO}_{2}$ and pressurized ethyl lactate as green processes to obtain lipid fractions enriched with GLnA from Spirulina [20]. With the aim of seeking an alternative bio-solvent with physicochemical properties close to those of hexane, in the current study limonene was investigated in combination with ethanol under pressurized conditions and compared to hexane for the extraction of valuable lipids from different marine organisms.

\section{2- Experimental}

\section{1- Samples and chemicals}

Spray-dried Spirulina was purchased from Algamar S.A. (Pontevedra, Spain) and stored under dry and dark conditions until used. Phormidium sp., Anabaena planctonica and Stigeoclonium sp. were kindly donated by the Spanish Bank of Algae (BEA) at the University of Las Palmas de Gran Canaria, Spain (http://bea.marinebiotechnology.org). Ethanol $99 \%$ and washed sea sand $(0.25-0.30 \mathrm{~mm}$ in diameter) were supplied by Panreac Quimica S.A. (Barcelona, Spain). D-Limonene (food-grade and kosher), acetyl chloride (98\%), GLnA (99\%), heptadecanoic acid (98\%), butylated hydroxytoluene (BHT, 99\%) and PUFA standards of marine source (PUFA No. 1) were purchased from Sigma-Aldrich (St. Louis, MO). $n$-Hexane 95\% was purchased from Labscan (Dublin, Ireland). Helium for GC-MS (premier quality 99.998\%) and nitrogen (technical quality 99\%) were obtained from Carburos 
Cite as:

Golmakani, M. T.; Mendiola, J. A.; Rezaei, K.; Ibáñez, Elena "Pressurized limonene as an alternative bio-solvent for the extraction of lipids from marine microorganisms" (2014) Journal of Supercritical Fluids 92: 1-7

http://dx.doi.org/10.1016/j.supflu.2014.05.001

Metalicos (Air Products Group, Madrid, Spain). Deionized water was obtained using a Milli-Q system from Millipore (Molsheim, France).

\section{2- Pressurized liquid extraction (PLE)}

PLE extraction experiments were performed using an Accelerated Solvent Extractor ${ }^{\mathrm{TM}}$ system (ASE 200, Dionex Corporation, Sunnyvale, CA) equipped with a solvent controller. Two g of microalgae and $4.0 \mathrm{~g}$ of sea sand were mixed and loaded into an 11-mL-volume extraction cell. The extraction cell was fitted with cellulose filter at both sides (from the inlet and outlet). In the first step, the extraction cell was filled with solvent and the pressure was increased to the desired level. Initial heat-up time was then applied depending on the extraction temperature. The heat-up time was automatically adjusted by the equipment. After the static stage of the extraction, the cell and the tubing were rinsed (with $60 \%$ of the cell volume) using fresh extraction solvent. Then, all the solvent present in the system was purged using $\mathrm{N}_{2}$ gas. The extract from this stage was collected in a vial and then pressure was released from the unit. The extracts were subjected to solvent removal using a rotary evaporator (Rotavapor R-210, Buchi Labortechnik AG, Flawil, Switzerland) for ethanol and hexane removal and an $\mathrm{N}_{2}$ stream at 100 ${ }^{\circ} \mathrm{C}$ for limonene removal.

\section{3- Solvent selection and temperature optimization}

To select the extracting solvent, four conditions were tested using $n$-hexane, $n$-hexane:ethanol $(1: 1$, $\mathrm{v} / \mathrm{v})$, limonene, and limonene:ethanol $(1: 1, \mathrm{v} / \mathrm{v})$ as solvents using a fixed pressure $(20.7 \mathrm{MPa})$ and a constant temperature $\left(180^{\circ} \mathrm{C}\right)$ and a total extraction time of $15 \mathrm{~min}$. For temperature optimization, extractions were performed using limonene:ethanol $(1: 1, \mathrm{v} / \mathrm{v})$ as solvent applying different temperatures of $50,100,150$, and $200{ }^{\circ} \mathrm{C}$ using a fixed pressure of $20.7 \mathrm{MPa}$ and a constant extraction 
Cite as:

Golmakani, M. T.; Mendiola, J. A.; Rezaei, K.; Ibáñez, Elena "Pressurized limonene as an alternative bio-solvent for the extraction of lipids from marine microorganisms" (2014) Journal of Supercritical Fluids 92: 1-7

http://dx.doi.org/10.1016/j.supflu.2014.05.001

time of $15 \mathrm{~min}$.

\section{4- Fatty acid analysis}

To determine the fatty acid contents of the lipid extracts, $30 \mathrm{mg}$ of dried extract from each sample was treated with $3.0 \mathrm{~mL}$ of ethanol-acetyl chloride $(95: 5, \mathrm{v} / \mathrm{v})$ solution. As an internal standard, $2.0 \mathrm{mg}$ heptadecanoic acid was added to the mixture and sealed in a $20 \mathrm{~mL}$ PTFE-lined vial under a nitrogen atmosphere and maintained at $85{ }^{\circ} \mathrm{C}$ for $1 \mathrm{~h}$. The temperature of the vial was then reduced to ambient conditions and after adding $1.0 \mathrm{~mL}$ water, it was shaken (vigorously) for $1 \mathrm{~min}$ and $3.0 \mathrm{~mL}$ hexane (containing $0.01 \%$ BHT to prevent the oxidation of double bonds during the isolation procedure) was added and produced ethyl ester derivatives were extracted. The hexane layer (upper phase) from this stage was transferred into a clean vial and injected into the GC-MS for qualitative and quantitative determination of fatty acid ethyl esters (FAEE) using a Shimadzu GC 2010 gas chromatography system (Kyoto, Japan) equipped with a Shimadzu AOC-20i autosampler and a split/splitless injector coupled to a QP-2010Plus single quadrupole mass spectrometer. The column was a 007-CW Carbowax, $12 \mathrm{~m} \times 0.1 \mathrm{~mm}$ i.d. fused silica capillary column with a $0.1 \mu \mathrm{m}$ film thickness (Quadrex, Woodbridge, CT, USA). The temperature levels in the injector, interface and ionization chamber were maintained at 220,240 , and $230{ }^{\circ} \mathrm{C}$, respectively. A gradient oven temperature programming starting at $100{ }^{\circ} \mathrm{C}$ with a ramp of $20^{\circ} \mathrm{C} / \mathrm{min}$ to $160^{\circ} \mathrm{C}$ and another ramp of $15^{\circ} \mathrm{C} / \mathrm{min}$ to $220^{\circ} \mathrm{C}$ with an 8 -min hold at $220^{\circ} \mathrm{C}$ was applied for the separation of FAEE. A $0.5-\mu \mathrm{L}$ sample was injected into the GC-MS with the injector in the split mode (split ratio at 1:10 level). Helium was used as the carrier gas. A solvent delay of 1.5 min was selected for the MS. A Shimadzu GC Solution software was used to process the data. Compounds were primarily identified by mass spectrometry in the SCAN mode using a mass interval ranging from 40 to $400 \mathrm{~m} / \mathrm{z}$. They were then identified by comparing the obtained 
Cite as:

Golmakani, M. T.; Mendiola, J. A.; Rezaei, K.; Ibáñez, Elena "Pressurized limonene as an alternative bio-solvent for the extraction of lipids from marine microorganisms" (2014) Journal of Supercritical Fluids 92: 1-7

http://dx.doi.org/10.1016/j.supflu.2014.05.001

retention times with those of standards and also by comparing their mass spectra with those of Wiley library. Quantitative determinations of the fatty acids were carried out using heptadecanoic acid as internal standard as mentioned earlier. The absence of heptadecanoic acid in the lipids was confirmed prior to the study. For each FAEE, a working curve was drawn using the weights and area ratios with respect to those of the internal standard.

\section{5- Statistical analysis}

Data were presented as means \pm standard deviations of at least two determinations. A general linear model (GLM) procedure from Statistical Analysis Software (SAS) version 9.1 (SAS Institute Inc., Cary, NC) was used to compare the mean values amongst the treatments at $P<0.05$. Multiple comparisons of means were carried out by using the LSD (least significant difference) test.

\section{3- Results and discussion}

\subsection{Selection of extraction solvent}

In a previous work [20], the possibilities of using pressurized ethyl lactate as an alternative green solvent for lipid extraction from Spirulina was investigated. A maximum extraction yield of $20.7 \%$ (w/w) and a GLnA recovery of $68.3 \%$ were obtained under PLE optimized conditions (ethanol:ethyl lactate, $1: 1, \mathrm{v} / \mathrm{v} ; 20.7 \mathrm{MPa}$ pressure; $180{ }^{\circ} \mathrm{C}$ temperatures and $15 \mathrm{~min}$ run time). Considering the common use of hexane in lipid extraction and the interest in finding green solvents that can be considered as alternate solvents to toxic organic solvents, limonene was chosen in the present study due to its similarities to hexane in terms of polarity. In order to be able to compare the results of this study with those of the previous study using ethyl lactate as extracting solvent [20], the abovementioned optimized conditions were applied in the present study as starting point to examine limonene and limonene:ethanol mixture $(1: 1, \mathrm{v} / \mathrm{v})$ to extract lipids from Spirulina and to obtain GLnAenriched fractions. Table 1 shows the results obtained in terms of total extraction yield, lipid 
Cite as:

Golmakani, M. T.; Mendiola, J. A.; Rezaei, K.; Ibáñez, Elena "Pressurized limonene as an alternative bio-solvent for the extraction of lipids from marine microorganisms" (2014) Journal of Supercritical Fluids 92: 1-7

http://dx.doi.org/10.1016/j.supflu.2014.05.001

concentration in the extract, GLnA concentration in the extract, lipid enrichment, lipid recovery and GLnA recovery, determined by using the following equations:

Total yield $(\%, \mathrm{w} / \mathrm{w})=[$ weight of the extract $(\mathrm{g}) /$ weight of Spirulina $(\mathrm{g})] \times 100$

Lipid concentration in the extract $(\%, \mathrm{w} / \mathrm{w})=[$ weight of the extracted lipids $(\mathrm{g}) /$ weight of the extract $(\mathrm{g})] \times 100$

GLnA concentration in the extract $=[$ weight of GLnA $(\mathrm{g}) /$ weight of the extract $(\mathrm{g})] \times 100$

Lipid enrichment $=$ lipid concentration in the extract $(\mathrm{w} / \mathrm{w}) /$ lipid concentration in the untreated Spirulina $(\mathrm{w} / \mathrm{w})$

Lipid recovery $=[$ Total yield of extract $(\%, \mathrm{w} / \mathrm{w}) \times$ lipid concentration in the extract $(\%, \mathrm{w} / \mathrm{w})] /$ lipid concentration in the untreated Spirulina $(\%, w / w)$

GLnA recovery $=[$ Total yield of extract $(\%, w / w) \times$ GLnA concentration in the extract $(\%, w / w)] /$ GLnA concentration in the untreated Spirulina $(\%, w / w)$

Lipid enrichment is the ratio of the final concentration of the lipid in the extract to its primary concentration in the untreated Spirulina $(8.6 \%, \mathrm{w} / \mathrm{w})$ while lipid recovery is defined as the ratio of the amount of lipid in the extract to its amount in the untreated Spirulina. Similarly, GLnA recovery is defined as the ratio of the amount of GLnA in the extract to its amount in the untreated Spirulina $(1.8 \%, \mathrm{w} / \mathrm{w})$ taking into consideration the total extraction yield. These parameters were compared with those achieved by employing hexane and hexane:ethanol as extraction solvents under the abovementioned optimized conditions.

Under given extraction conditions, different solvents from the current study showed completely different behaviours in terms of extraction yield. For instance, extractions using pure limonene resulted in a yield somewhat higher than that found for pure hexane (8.1\% compared to $5.6 \%$, respectively). However, in comparison with the yield obtained with ethanol as co-solvent for limonene or hexane, it was almost half (around 14\% for both). This finding can be related to the levels of polar lipids in Spirulina, namely, phospholipids, glycolipids and other cell membrane lipids [21]. In terms of lipid concentrations in the extracts, the quantities varied significantly from $31.4 \%$ (when using pure 
Cite as:

Golmakani, M. T.; Mendiola, J. A.; Rezaei, K.; Ibáñez, Elena "Pressurized limonene as an alternative bio-solvent for the extraction of lipids from marine microorganisms" (2014) Journal of Supercritical Fluids 92: 1-7

http://dx.doi.org/10.1016/j.supflu.2014.05.001

${ }_{178}$ limonene) to $38.9 \%$ (when using hexane:ethanol, 1:1, v/v). On the other hand, the levels of GLnA

were similar for all the conditions studied, with no significant differences among them. Recoveries for GLnA ranged from $28.5 \%$ when using hexane to $67.8 \%$ when using hexane:ethanol $(1: 1, \mathrm{v} / \mathrm{v})$ as the solvents for lipid extraction. The recovery for the latter case was not significantly different from the one achieved when using limonene:ethanol $(1: 1, \mathrm{v} / \mathrm{v})$ as solvent. Such finding indicates that the selectivity of GLnA extraction can be improved simply by using a more appropriate solvent such as hexane:ethanol or limonene:ethanol mixtures. This shows that limonene behaves, as expected, very close to hexane for lipid extraction [3]. Figure 1 shows the chromatograms of the fatty acid profiles obtained by using the different solvents. Fatty acid profiles for different extracts were found at very similar quantities thus indicating that the extraction solvent has no significant impact on the fatty acid composition. It is worth mentioning that fatty acid compositions of extracts obtained in the present study were similar to those reported in literature using hexane $[22,23]$ or supercritical $\mathrm{CO}_{2}$ extraction $[15,17,24]$. When comparing the pressurized limonene with the pressurized hexane for the extraction of lipids from Spirulina, it was found that limonene provided higher lipid extraction yields than did pure hexane. In fact, that could be related to the higher density of limonene. Therefore, it can be concluded that hexane can easily be replaced by limonene and that the use of this solvent in PLE has several advantages in terms of yield, recoveries and environmental impact.

\subsection{Solvent temperature optimization}

It is well known that one of the main factors that influences the PLE process in terms of yield and selectivity is the extraction temperature $[19,25]$, which was also confirmed for GLnA extraction from Spirulina using PLE with ethyl lactate as extraction solvent [20]. Therefore, once the extracting solvent was selected for achieving the maximum lipids and GLnA recoveries (limonene:ethanol, 1:1, v/v), 
Cite as:

Golmakani, M. T.; Mendiola, J. A.; Rezaei, K.; Ibáñez, Elena "Pressurized limonene as an alternative bio-solvent for the extraction of lipids from marine microorganisms" (2014) Journal of Supercritical Fluids 92: 1-7

http://dx.doi.org/10.1016/j.supflu.2014.05.001

temperature was studied as the main parameter for the optimization of the PLE process. A wide range of temperatures was selected: $50,100,150$, and $200{ }^{\circ} \mathrm{C}$. Extraction pressure and time were kept constant as those of the previous experiments; that is, $20.7 \mathrm{MPa}$ and $15 \mathrm{~min}$, respectively. Table 2 shows the results obtained by using limonene:ethanol $(1: 1, \mathrm{v} / \mathrm{v})$ at different temperatures. As can be seen, the extraction yield increases from $7.5 \%\left(\right.$ at $50^{\circ} \mathrm{C}$ ) up to $17.6 \%\left(\right.$ at $200^{\circ} \mathrm{C}$ ). While at the same time quantities of lipids and GLnA concentration decreased significantly. Considering the higher yields, the global effect is that higher lipid and GLnA recoveries can be achieved at the highest temperature examined in the present study (almost $70.0 \%$ of lipid recovery and $73.6 \%$ GLnA recovery at $200^{\circ} \mathrm{C}$ ). By analysing these results, we can conclude that the best conditions to obtain valuable lipid extracts from Spirulina within the tested ranges were: limonene:ethanol $(1: 1, \mathrm{v} / \mathrm{v})$ as solvent, $200{ }^{\circ} \mathrm{C}$ of extraction temperature; $20.7 \mathrm{MPa}$ as extraction pressure and a total of $15 \mathrm{~min}$ as extraction time. Results obtained were similar to those achieved using ethanol:ethyl lactate $(1: 1, \mathrm{v} / \mathrm{v})$ as extraction solvent [20] at $180^{\circ} \mathrm{C}, 20.7 \mathrm{MPa}$ and 15 min as extraction conditions providing an extraction yield of $20.0 \%$ and GLnA recovery of $68.0 \%$.

\subsection{Application of the PLE process using limonene:ethanol as extracting solvent to} other cyanobacteria and microalgae

As mentioned, 2 different cyanobacteria, namely Anabaena planctonica and Phormidium, and one green microalgae (Stigeoclonium) were selected to test the efficacy of the PLE process using limonene:ethanol towards the extraction of lipids and, more specifically, towards the differential extraction of fatty acids (GLnA; saturated fatty acids, SAFA; monounsaturated fatty acids, MUFA and PUFA). Table 3 shows the total extraction yield, lipid and GLnA concentrations and recoveries, and lipid enrichment of the different cyanobacteria and microalgae studied. As can be observed, results 
Cite as:

Golmakani, M. T.; Mendiola, J. A.; Rezaei, K.; Ibáñez, Elena "Pressurized limonene as an alternative bio-solvent for the extraction of lipids from marine microorganisms" (2014) Journal of Supercritical Fluids 92: 1-7

http://dx.doi.org/10.1016/j.supflu.2014.05.001

${ }^{224}$ were very much dependent on the type of microorganisms, with total yields ranging from $3.1 \%$ (for

Anabaena) to $16.7 \%$ (for Stigeoclonium). In terms of percentage of lipids in the extracts obtained, these ranged from $6.0 \%$ (for Anabaena) to almost $32.0 \%$ for Stigeoclonium, being this value really close to the one obtained for Spirulina. The wide variability on the lipid yield depends mainly on the microorganism and the culture conditions, as reported in other studies [26, 27]. The best results in terms of extraction of GLnA were obtained using Stigeoclonium, where this fatty acid was more than $38 \%, \mathrm{w} / \mathrm{w}$, implying a $96.4 \%$ of recovery as referred to the value of the untreated organism. As can be seen in Table 4, the fatty acid profiles of the other cyanobacteria were quite different and therefore the results obtained also differed among different algae studied here. Comparing the results for raw and treated microalgae in Table 4 indicates that the selectivity of the extraction process depends mainly on the solvent used (in this case limonene:ethanol, 1:1, v/v) and type of the fatty acids that are concentrated (i.e., polar, nonpolar or medium-polarity lipids). The concentrations of several fatty acids are clearly increased after the extraction process. For instance, the high levels of fatty acids in Stigeoclonium extract could be related to the presence of phosphatase [28], which could be responsible for the degradation of phospholipids in the Stigeoclonium cell wall, and therefore, the extraction rates are enhanced. Moreover, the levels of PUFAs from the C18 series (C18:2 and C18:3) are clearly increased after the extraction with limonene:ethanol indicating that these fatty acids can be mainly contained in medium-polarity lipids such as monogalactosyldiglycerides. Therefore, depending on the final use of the extracts, one can tune the selectivity of the process to concentrate unsaturated fatty acids or saturated ones (Figure 2). A good example is the case of Stigeoclonium that, as mentioned by Praveenkumar et al [16], might be a promising feedstock source for biodiesel production since it possessed fatty acids from the $\mathrm{C} 16$ and $\mathrm{C} 18$ series. But, in order to fulfil the requirements for biodiesel production according to the European standard EN14214, it should not contain C18:3 at a level higher than $12 \%$. Therefore, if the final goal is to concentrate GLnA, the developed process in this study is 
Cite as:

Golmakani, M. T.; Mendiola, J. A.; Rezaei, K.; Ibáñez, Elena "Pressurized limonene as an alternative bio-solvent for the extraction of lipids from marine microorganisms" (2014) Journal of Supercritical Fluids 92: 1-7

http://dx.doi.org/10.1016/j.supflu.2014.05.001

preferred. But, to use these microalgae for biodiesel production, different solvent compositions should be obtained. On the other hand, the strong cell wall present in Anabaena can be the reason for the low lipid concentration in its extract. This cell wall is especially strong in some of their cells called heterocysts, which are composed of several layers to reduce oxygen permeability [29]. For Anabaena, the amount of lipids extracted was similar to the original composition of the raw sample and only a small increase in the unsaturated fatty acids was observed (Table 4 and Figure 2). Due to the higher levels of C16:0 in Anabaena cyanobacteria, they have been suggested as potential sources for biodiesel production since proportion of SAFA and MUFA is preferred for increasing energy yield and oxidative stability [30].

Meanwhile, the extraction of lipids from Phormidium using this method was more selective (Fig. 3), since FA levels in the extracts were higher. This fact could be due to the high concentration of free fatty acids in Phormidium, which was previously reported by Rodriguez-Meizoso et al [31] and El Semary [32].

\section{4- Conclusion}

It can be concluded that the proposed process involving the use of limonene:ethanol $(1: 1, \mathrm{v} / \mathrm{v})$ as extraction solvent at $200{ }^{\circ} \mathrm{C}$ and $20.7 \mathrm{MPa}$ for $15 \mathrm{~min}$ of extraction can be an interesting option to be used as a selective process to obtain lipid extracts enriched in valuable fatty acids, mainly those present in the medium-polarity lipids, in a short extraction time. Extracts obtained with this method can be directly used in food, pharmaceutical or cosmetic preparations or can be employed as a new source for biodiesel production, depending on the species used. 
Cite as:

Golmakani, M. T.; Mendiola, J. A.; Rezaei, K.; Ibáñez, Elena "Pressurized limonene as an alternative bio-solvent for the extraction of lipids from marine microorganisms" (2014) Journal of Supercritical Fluids 92: 1-7

http://dx.doi.org/10.1016/j.supflu.2014.05.001

\section{5- Acknowledgement}

This work has been financed by the Spanish Ministry of Science (Project AGL2011-29857-C03-01).

M.T. Golmakani wishes to thank Iranian Ministry of Science, Research, and Technology (\# 42/4/52566) and Research council of the University of Tehran for supporting his stay in CIAL-CSIC, Spain. Authors would like to thank Spanish Bank of Algae (BEA) at University of Las Palmas de Gran Canaria, Spain (http://bea.marinebiotechnology.org) for the donation of samples.

\section{6- References}

[1] H. Misirli, F.M. Domaç, G. Somay, Ö. Araal, B. Özer, T. Adigüzel, N-hexane induced polyneuropathy: A clinical and electrophysiological follow up, Electromyography and Clinical Neurophysiology, 48 (2008) 103-108.

[2] L.A. Johnson, E.W. Lusas, Comparison of alternative solvents for oils extraction, Journal of the American Oil Chemists' Society, 60 (1983) 229-242.

[3] M. Virot, V. Tomao, C. Ginies, F. Visinoni, F. Chemat, Green procedure with a green solvent for fats and oils' determination: Microwave-integrated Soxhlet using limonene followed by microwave Clevenger distillation, Journal of Chromatography A, 1196-1197 (2008) 147-152.

[4] S.X. Liu, P.K. Mamidipally, Quality comparison of rice bran oil extracted with d-limonene and hexane, Cereal Chemistry, 82 (2005) 209-215.

[5] P.K. Mamidipally, S.X. Liu, First approach on rice bran oil extraction using limonene, European Journal of Lipid Science and Technology, 106 (2004) 122-125.

[6] M. Virot, V. Tomao, C. Ginies, F. Chemat, Total Lipid Extraction of Food Using d-Limonene as an Alternative to n-Hexane, Chromatographia, 68 (2008) 311-313.

[7] Z. Chemat-Djenni, M.A. Ferhat, V. Tomao, F. Chemat, Carotenoid extraction from tomato using a green solvent resulting from orange processing waste, Journal of Essential Oil-Bearing Plants, 13 (2010) 139-147.

[8] M. Castro-Puyana, M. Herrero, I. Urreta, J.A. Mendiola, A. Cifuentes, E. Ibáñez, S. SuárezAlvarez, Optimization of clean extraction methods to isolate carotenoids from the microalga Neochloris oleoabundans and subsequent chemical characterization using liquid chromatography tandem mass spectrometry, Analytical and Bioanalytical Chemistry, (2013) 1-10.

[9] C. Dejoye Tanzi, M. Abert Vian, F. Chemat, New procedure for extraction of algal lipids from wet biomass: A green clean and scalable process, Bioresource Technology, 134 (2013) 271-275.

[10] A. Cháfer, R. Muñoz, M.C. Burguet, A. Berna, The influence of the temperature on the liquidliquid equlibria of the mixture limonene + ethanol $+\mathrm{H}_{2} \mathrm{O}$, Fluid Phase Equilibria, 224 (2004) 251-256.

[11] M.A. Borowitzka, N.R. Moheimani, Sustainable biofuels from algae, Mitigation and Adaptation Strategies for Global Change, 18 (2013) 13-25. 
Cite as:

Golmakani, M. T.; Mendiola, J. A.; Rezaei, K.; Ibáñez, Elena "Pressurized limonene as an alternative bio-solvent for the extraction of lipids from marine microorganisms" (2014) Journal of Supercritical Fluids 92: 1-7

http://dx.doi.org/10.1016/j.supflu.2014.05.001

[12] Z. Cohen, Y. Heimer, Production of Polyunsaturated Fatty Acids (EPA, ARA and GLA) by the Microalgae Porphyridium and Spirulina, in: D.J. Kyle, C. Ratledge (Eds.) Industrial Applications of Single Cell Oils, AOCS Publishing, 1992. doi:10.1201/9781439821855.ch14

[13] Y.-Y. Fan, R.S. Chapkin, Importance of dietary $\gamma$-linolenic acid in human health and nutrition, The Journal of Nutrition, 128 (1998) 1411-1414.

[14] M.G. Sajilata, R.S. Singhal, M.Y. Kamat, Supercritical $\mathrm{CO}_{2}$ extraction of $\gamma$-linolenic acid (GLA) from Spirulina platensis ARM 740 using response surface methodology, Journal of Food Engineering, 84 (2008) 321-326.

[15] R.L. Mendes, A.D. Reis, A.P. Pereira, M.T. Cardoso, A.F. Palavra, J.P. Coelho, Supercritical $\mathrm{CO}_{2}$ extraction of $\gamma$-linolenic acid (GLA) from the cyanobacterium Arthrospira (Spirulina) maxima: experiments and modeling, Chemical Engineering Journal, 105 (2005) 147-151.

[16] R. Praveenkumar, K. Johncy, D. MubarakAli, D. Vijayan, N. Thajuddin, M. Gunasekaran, Demonstration of increased lipid accumulation potential of Stigeoclonium sp., Kütz. BUM11007 under nitrogen starved regime: A new source of lipids for biodiesel production, Journal of Biobased Materials and Bioenergy, 6 (2012) 209-213.

[17] J.A. Mendiola, L. Jaime, S. Santoyo, G. Reglero, A. Cifuentes, E. Ibañez, F.J. Señoráns, Screening of functional compounds in supercritical fluid extracts from Spirulina platensis, Food Chemistry, 102 (2007) 1357-1367.

[18] S. Santoyo, M. Herrero, F.J. Señorans, A. Cifuentes, E. Ibáñez, L. Jaime, Functional characterization of pressurized liquid extracts of Spirulina platensis, European Food Research and Technology, 224 (2006) 75-81.

[19] M. Herrero, P.J. Martín-Álvarez, F.J. Señoráns, A. Cifuentes, E. Ibáñez, Optimization of accelerated solvent extraction of antioxidants from Spirulina platensis microalga, Food Chemistry, 93 (2005) 417-423.

[20] M.-T. Golmakani, J.A. Mendiola, K. Rezaei, E. Ibáñez, Expanded ethanol with $\mathrm{CO}_{2}$ and pressurized ethyl lactate to obtain fractions enriched in $\gamma$-Linolenic Acid from Arthrospira platensis (Spirulina), The Journal of Supercritical Fluids, 62 (2012) 109-115.

[21] M. Herrero, M.J. Vicente, A. Cifuentes, E. Ibáñez, Characterization by high-performance liquid chromatography/electrospray ionization quadrupole time-of-flight mass spectrometry of the lipid fraction of Spirulina platensis pressurized ethanol extract, Rapid Communications in Mass Spectrometry, 21 (2007) 1729-1738.

[22] M. Herrero, E. Ibáñez, J. Señoráns, A. Cifuentes, Pressurized liquid extracts from Spirulina platensis microalga: Determination of their antioxidant activity and preliminary analysis by micellar electrokinetic chromatography, Journal of Chromatography A, 1047 (2004) 195-203.

[23] L. Gouveia, A. Oliveira, Microalgae as a raw material for biofuels production, Journal of Industrial Microbiology \& Biotechnology, 36 (2009) 269-274.

[24] G. Andrich, A. Zinnai, U. Nesti, F. Venturi, R. Fiorentini, Supercritical fluid extraction of oil from microalga Spirulina (Arthrospira) platensis, Acta Alimentaria, 35 (2006) 195-203.

[25] M. Herrero, A. Cifuentes, E. Ibañez, Sub- and supercritical fluid extraction of functional ingredients from different natural sources: Plants, food-by-products, algae and microalgae: A review, Food Chemistry, 98 (2006) 136-148.

[26] R. Li, M.M. Watanabe, Fatty acid profiles and their chemotaxonomy in planktonic species of Anabaena (cyanobacteria) with straight trichomes, Phytochemistry, 57 (2001) 727-731.

[27] I.P. Maslova, E.A. Mouradyan, S.S. Lapina, G.L. Klyachko-Gurvich, D.A. Los, Lipid fatty acid composition and thermophilicity of cyanobacteria, Russian Journal of Plant Physiology, 51 (2004) 353-360. 
Golmakani, M. T.; Mendiola, J. A.; Rezaei, K.; Ibáñez, Elena "Pressurized limonene as an alternative bio-solvent for the extraction of lipids from marine microorganisms" (2014) Journal of Supercritical Fluids 92: 1-7

http://dx.doi.org/10.1016/j.supflu.2014.05.001

353 [28] K.M. Michetti, P.I. Leonardi, E.J. Caceres, Cytochemical localization of acid phosphatase in ${ }_{354}$ Stigeoclonium tenue (Chaetophorales, Chlorophyceae), Biocell, 30 (2006) 491-496.

${ }_{355}$ [29] K. Nicolaisen, A. Hahn, E. Schleiff, The cell wall in heterocyst formation by Anabaena sp. PCC 356 7120, Journal of Basic Microbiology, 49 (2009) 5-24.

${ }_{357}^{35}$ [30] S.G. Musharraf, M.A. Ahmed, N. Zehra, N. Kabir, M.I. Choudhary, A.U. Rahman, Biodiesel ${ }_{358}$ production from microalgal isolates of southern Pakistan and quantification of FAMEs by GC-MS/MS 359 analysis, Chemistry Central Journal, 6 (2012).

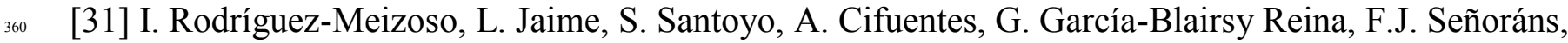
361 E. Ibáñez, Pressurized fluid extraction of bioactive compounds from Phormidium species, Journal of 362 Agricultural and Food Chemistry, 56 (2008) 3517-3523.

${ }_{363}$ [32] N.A. El Semary, The antimicrobial profile of extracts of a Phormidium-like cyanobacterium changes with phosphate levels, World Journal of Microbiology and Biotechnology, 28 (2012) 585-593. 
Cite as:

Golmakani, M. T.; Mendiola, J. A.; Rezaei, K.; Ibáñez, Elena "Pressurized limonene as an alternative bio-solvent for the extraction of lipids from marine microorganisms" (2014) Journal of Supercritical Fluids 92: 1-7

http://dx.doi.org/10.1016/j.supflu.2014.05.001

Figure captions

Figure 1. Changes in the fatty acid profile of Spirulina extracted with different solvents compared to untreated Spirulina (1=C16:0: Palmitic acid; 2=C16:1: Palmitoleic acid; 3=C18:0: Stearic acid; 4=C18:1: Oleic acid; 5=C18:2: Linoleic acid; C18:3: $6=\gamma$-Linolenic acid).

Figure 2. Comparison of fatty acid profiles of raw and extracted samples. Data shown are in $\%(\mathrm{w} / \mathrm{w})$. SAFA, Saturated fatty acids; MUFA, Monounsaturated fatty acids; PUFA, Polyunsaturated fatty acids. 

2 Table 1. Total extraction yield, lipid concentration and concentration of $\gamma$-linolenic acid (GLnA) in Spirulina applying pressurized liquid extraction at 20.7 MPa and 180

$3 \quad{ }^{\circ} \mathrm{C}$ for 15 min using different solvents

\begin{tabular}{|c|c|c|c|c|c|c|}
\hline Solvent & Total extraction yield $(\%, w / w)$ & $\begin{array}{l}{ }_{0} \text { Lipid concentration in the extract (\%, } \\
\text { w/w) }\end{array}$ & $\begin{array}{l}\text { GLnA concentration in the extract (\%, } \\
\text { w/w) }\end{array}$ & Lipid enrichment $^{\dagger}$ & Lipid recovery $^{\dagger}$ & GLnArecovery \\
\hline Limonene & $8.1 \pm 0.6^{\mathrm{b} \ddagger}$ & $31.4 \pm 2.2^{\mathrm{b}}$ & $8.3 \pm 0.6^{\mathrm{a}}$ & $3.7 \pm 0.3^{\mathrm{a}}$ & $29.6 \pm 2.1^{\mathrm{b}}$ & $38.4 \pm 2.7^{b}$ \\
\hline $\begin{array}{l}\text { Limonene:Ethanol } \\
(1: 1, \mathrm{v} / \mathrm{v})\end{array}$ & $14.4 \pm 1.0^{\mathrm{a}}$ & $34.7 \pm 2.5^{\mathrm{ab}}$ & $7.7 \pm 0.5^{\mathrm{a}}$ & $4.0 \pm 0.3^{\mathrm{a}}$ & $58.1 \pm 4.1^{\mathrm{a}}$ & $63.0 \pm 4.5^{\mathrm{a}}$ \\
\hline Hexane & $5.6 \pm 0.4^{c}$ & $35.8 \pm 2.5^{\mathrm{ab}}$ & $8.9 \pm 0.6^{\mathrm{a}}$ & $4.2 \pm 0.3^{\mathrm{a}}$ & $23.3 \pm 1.6^{\mathrm{b}}$ & $28.5 \pm 2.0^{\mathrm{b}}$ \\
\hline $\begin{array}{l}\text { Hexane:Ethanol } \\
(1: 1, \mathrm{v} / \mathrm{v})\end{array}$ & $13.2 \pm 0.9^{\mathrm{a}}$ & $38.9 \pm 2.8^{\mathrm{a}}$ & $9.0 \pm 0.6^{\mathrm{a}}$ & $4.5 \pm 0.3^{\mathrm{a}}$ & $60.1 \pm 4.3^{\mathrm{a}}$ & $67.8 \pm 4.8^{\mathrm{a}}$ \\
\hline
\end{tabular}

5 Yield expressed as g of dry extract/100 g Spirulina (w/w)

$6 \quad{ }^{\dagger}$ Values relative to total lipid content in untreated Spirulina

$7 \quad$ "Values relative to total GLnA content in untreated Spirulina

$8 \quad{ }^{\ddagger}$ Mean \pm SD $(n=2)$; in each column, means identified with the same letter are not significantly different $(p>0.05)$. 
14 Table 2. Total extraction yield, lipid concentration and concentration of $\gamma$-linolenic acid (GLnA) in Spirulina applying pressurized liquid extraction at 20.7 MPa, 15 min,

15 using limonene:ethanol $(1: 1, \mathrm{v} / \mathrm{v})$ as extraction solvent at different temperatures

\begin{tabular}{|c|c|c|c|c|c|c|}
\hline Temperature $\left({ }^{\circ} \mathrm{C}\right)$ & Total extraction yield $(\%, \mathrm{w} / \mathrm{w})^{\diamond}$ & $\begin{array}{l}\text { Lipids concentration in the } \\
\text { extract }(\%, w / w)\end{array}$ & $\begin{array}{l}\text { GLnA concentration in the } \\
\text { extract }(\%, w / w)\end{array}$ & Lipid enrichment $^{\dagger}$ & Lipid recovery $^{\dagger}$ & GLnA recovery \\
\hline 50 & $7.5 \pm 0.2^{\mathrm{df}}$ & $42.9 \pm 3.0^{\mathrm{a}}$ & $10.2 \pm 0.7^{\mathrm{a}}$ & $5.0 \pm 0.4^{\mathrm{a}}$ & $37.6 \pm 2.7^{\mathrm{c}}$ & $43.6 \pm 3.1^{\mathrm{c}}$ \\
\hline 100 & $10.4 \pm 0.1^{\mathrm{c}}$ & $39.5 \pm 2.8^{\mathrm{ab}}$ & $8.9 \pm 0.6^{\mathrm{ab}}$ & $4.6 \pm 0.3^{\mathrm{ab}}$ & $47.7 \pm 3.4^{\mathrm{bc}}$ & $52.7 \pm 3.7^{\mathrm{bc}}$ \\
\hline 150 & $12.1 \pm 0.1^{\mathrm{b}}$ & $39.5 \pm 2.8^{\mathrm{ab}}$ & $8.7 \pm 0.6^{\mathrm{ab}}$ & $4.6 \pm 0.3^{\mathrm{ab}}$ & $56.1 \pm 4.0^{\mathrm{b}}$ & $60.4 \pm 4.3^{\mathrm{b}}$ \\
\hline 200 & $17.6 \pm 0.2^{\mathrm{a}}$ & $33.7 \pm 2.4^{\mathrm{b}}$ & $7.3 \pm 0.5^{b}$ & $3.9 \pm 0.3^{b}$ & $69.6 \pm 4.9^{\mathrm{a}}$ & $73.6 \pm 5.2^{\mathrm{a}}$ \\
\hline
\end{tabular}

16 Yield expressed as g of dry extract/100 g Spirulina (w/w)

$17{ }^{\dagger}$ Values relative to total lipid content in untreated Spirulina

18 "Values relative to total GLnA content in untreated Spirulina

$19{ }^{\ddagger}$ Mean $\pm \mathrm{SD}(\mathrm{n}=2)$; in each column, means with different letters are significantly different $(p<0.05)$.

20

21

22

23 
26 Table 3.- Total extraction yield, lipid concentration and concentration of $\gamma$-linolenic acid (GLnA) in the different microalgae applying pressurized liquid extraction at

27 the optimized extraction conditions (limonene:ethanol, 1:1, v/v; $200^{\circ} \mathrm{C} ; 20.7 \mathrm{MPa}$ and $15 \mathrm{~min}$ ).

\begin{tabular}{|c|c|c|c|c|c|c|}
\hline & $\begin{array}{l}\text { Total extraction } \\
\text { yield }(\%, w / w)^{\diamond}\end{array}$ & $\begin{array}{l}\text { Lipid concentration } \\
\text { in the extract } \\
(\%, \mathrm{w} / \mathrm{w})\end{array}$ & $\begin{array}{l}\text { GLA concentration } \\
\text { in the extract } \\
(\%, \mathrm{w} / \mathrm{w})\end{array}$ & $\begin{array}{l}\text { Lipid } \\
\text { enrichment }^{\dagger}\end{array}$ & $\begin{array}{l}\text { Lipid } \\
\text { recovery }^{\dagger}\end{array}$ & $\begin{array}{l}\text { GLnA } \\
\text { recovery* }\end{array}$ \\
\hline Anabaena & $3.1 \pm 0.5$ & $6.0 \pm 1.1$ & $1.3 \pm 0.4$ & $3.1 \pm 0.1$ & $9.7 \pm 2.0$ & $17.4 \pm 1.2$ \\
\hline Phormidium & $6.8 \pm 1.4$ & $13.0 \pm 1.3$ & -- & $7.1 \pm 1.2$ & $48.3 \pm 5.5$ & -- \\
\hline Stigeoclonium & $16.7 \pm 0.1$ & $31.9 \pm 1.7$ & $6.9 \pm 0.8$ & $5.9 \pm 0.1$ & $98.6 \pm 3.2$ & $96.4 \pm 3.8$ \\
\hline
\end{tabular}

28

29 Yield expressed as g of dry extract/100 g of raw material (w/w)

$30{ }^{\dagger}$ Values relative to lipid contents in the untreated microalgae

31 "Values relative to total GLnA contents in the untreated microalgae

32

33

34 
36

37 Table 4. Individual contribution (\%, w/w) of different fatty acids detected in the samples compared to the total lipid content

38

\begin{tabular}{|c|c|c|c|c|c|c|c|}
\hline \multirow{2}{*}{ Type of microorganism } & \multicolumn{7}{|c|}{ Type of fatty acid } \\
\hline & C16:0 & $\mathrm{C} 16: 1$ & C16:2 & C18:0 & C18:1 & C18:2 & C18:3 \\
\hline Anabaena untreated & $59.53 \pm 6.09$ & $14.75 \pm 1.94$ & - & $4.99 \pm 0.63$ & $3.95 \pm 0.18$ & $4.69 \pm 0.33$ & $12.09 \pm 0.08$ \\
\hline Anabaena extract ${ }^{\ominus}$ & $47.49 \pm 3.79$ & $9.68 \pm 0.21$ & - & $16.37 \pm 1.10$ & $5.39 \pm 0.47$ & $4.96 \pm 0.71$ & $16.11 \pm 0.56$ \\
\hline Phormidium untreated & $35.92 \pm 1.71$ & $5.93 \pm 0.76$ & $46.52 \pm 5.50$ & $11.63 \pm 1.31$ & - & - & - \\
\hline Phormidium extract ${ }^{\ominus}$ & $46.96 \pm 1.12$ & $27.09 \pm 2.23$ & $21.03 \pm 0.13$ & $4.93 \pm 0.03$ & - & - & - \\
\hline Stigeoclonium untreated & $39.21 \pm 3.20$ & $1.58 \pm 0.02$ & $2.78 \pm 0.41$ & $5.83 \pm 0.35$ & $19.94 \pm 1.36$ & $8.50 \pm 0.49$ & $22.17 \pm 1.39$ \\
\hline Stigeoclonium extract ${ }^{\diamond}$ & $36.87 \pm 0.13$ & $2.52 \pm 0.09$ & $1.59 \pm 0.02$ & $1.43 \pm 0.20$ & $2.28 \pm 0.25$ & $17.03 \pm 0.68$ & $38.29 \pm 3.29$ \\
\hline Spirulina untreated & $36.82 \pm 5.38$ & $17.39 \pm 1.98$ & $1.29 \pm 0.01$ & $1.17 \pm 0.03$ & $4.59 \pm 0.19$ & $20.12 \pm 1.43$ & $19.92 \pm 1.12$ \\
\hline Spirulina extract ${ }^{\diamond}$ & $41.97 \pm 5.28$ & $11.53 \pm 0.77$ & $1.48 \pm 0.07$ & $1.28 \pm 0.05$ & $2.66 \pm 0.18$ & $17.83 \pm 0.68$ & $23.25 \pm 1.57$ \\
\hline
\end{tabular}

39

$40{ }^{\circ}$ PLE extracts done with limonene:ethanol (1:1, v/v) as extraction solvent, $200{ }^{\circ} \mathrm{C}, 20.7 \mathrm{MPa}$, and 15 min of extraction time

41 "C16:0: Palmitic acid; C16:1: Palmitoleic acid; C16:2: Hexadecadienoic acid; C18:0: Stearic acid; C18:1: Oleic acid; C18:2: Linoleic acid; C18:3: $\gamma$-Linolenic acid 